\title{
Article
}

\section{Bridging the gap between research and agile practice: an evolutionary model}

Barroca, Leonor, Sharp, Helen, Salah, Dina, Taylor, Katie Jane and Gregory, Peggy

Available at http://clok.uclan.ac.uk/11795/

Barroca, Leonor, Sharp, Helen, Salah, Dina, Taylor, Katie Jane ORCID: 00000003-4840-9991 and Gregory, Peggy ORCID: 0000-0001-7891-6666 (2015) Bridging the gap between research and agile practice: an evolutionary model. International Journal of System Assurance Engineering and Management . ISSN 0975-6809

It is advisable to refer to the publisher's version if you intend to cite from the work. http://dx.doi.org/10.1007/s13198-015-0355-5

For more information about UCLan's research in this area go to http://www.uclan.ac.uk/researchgroups/ and search for < name of research Group>.

For information about Research generally at UCLan please go to http://www.uclan.ac.uk/research/

All outputs in CLoK are protected by Intellectual Property Rights law, including Copyright law. Copyright, IPR and Moral Rights for the works on this site are retained by the individual authors and/or other copyright owners. Terms and conditions for use of this material are defined in the policies page.

\section{CLoK}

Central Lancashire online Knowledge www.clok.uclan.ac.uk

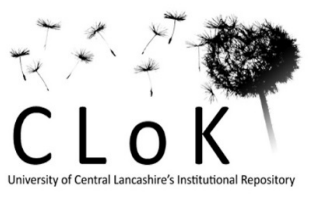




\title{
Bridging the gap between research and agile practice: an evolutionary model
}

\author{
Leonor Barroca, Helen Sharp and Dina Salah \\ The Open University \\ Milton Keynes, Herts \\ MK76AA \\ +441908653638 \\ (leonor.barroca, helen.sharp and dina.salah)@open.ac.uk \\ Katie Taylor and Peggy Gregory \\ University of Central Lancashire \\ Preston, Lancs \\ PR1 2HE \\ +44 0117289 (3321 or 3284) \\ (kjtaylor and ajgregory)@uclan.ac.uk
}

\begin{abstract}
There is wide acceptance in the software engineering field that industry and research can gain significantly from each other and there have been several initiatives to encourage collaboration between the two. However there are some often-quoted challenges in this kind of collaboration. For example, that the timescales of research and practice are incompatible, that research is not seen as relevant for practice, and that research demands a different kind of rigour than practice supports. These are complex challenges that are not always easy to overcome. Since the beginning of 2013 we have been using an approach designed to address some of these challenges and to bridge the gap between research and practice, specifically in the agile software development arena. So far we have collaborated successfully with three partners and have investigated three practitioner-driven challenges with agile. The model of collaboration that we adopted has evolved with the lessons learned in the first two collaborations and been modified for the third. In this paper we introduce the collaboration model, discuss how it addresses the collaboration challenges between research and practice and how it has evolved, and describe the lessons learned from our experience.
\end{abstract}

\section{Keywords}

Agile Software Development, Action Research, Collaboration Model 


\section{INTRODUCTION}

The Agile Research Network was set up in 2013 as a result of collaboration between the authors' institutions and an industry body, the DSDM Consortium (dsdm.org, Gregory et al. 2014, Sharp et al. 2014b). It aims to bridge the gap between academia and industry in the field of agile software development by providing a model for both the delivery of timely and relevant research of use to practitioners, and wider dissemination through white papers and research publications.

Agile software development evolved during the 1990's as a response by 'grass root' developers to counter some of the known problems of the Waterfall lifecycle (Highsmith 2002). The focus of agile methods is on frequent delivery of working and fit-for-purpose software, in an iterative and incremental way, using a lightweight, people-centred approach, and a flexible and reflexive mind-set. A critical early point in the history of agile methods was the publication of the agile manifesto in 2001 (agilemanifesto.org). From the early days there was a variety of methods: Extreme Programming (Beck 2000), Scrum (Schwaber 2004), Crystal (Cockburn 2004), Dynamic Systems Development Method (DSDM) (DSDM Consortium, 2012) amongst others. Method authors were usually practicing consultants, which indicates that the roots of agile methods are grounded in practical experience (Agerfalk and Fitzgerald 2006).

Agile methods have become more mainstream as organisations seek to scale-up the benefits claimed. However, the impact this way of working has on individuals, products and the wider organisation is not well understood. Research that gains greater understanding of how agile methods work in industrial and commercial situations is required to assist organisational uptake. Recent systematic literature reviews of research in agile development call for more empirical research, more focus on mature agile contexts, and more research with industrial relevance (Abrahamsson et al. 2009; Dingsøyr et al. 2008; Dingsøyr et al. 2012).

While collaboration between individual researchers and practitioners can yield solid benefits for the researcher, and useful insights for the practitioner involved, it has also limitations due to issues of time, priorities and authority. Although a practitioner or group of practitioners may be motivated to engage in research, their priority will be to meet the demands of their job rather than those of the research. Effort expended on supporting research is an 'overhead', and in addition, individuals' authority may be limited.

Greater benefits can be achieved for both sides by involving organisations more formally, and this inevitably involves funding and more careful scheduling. This leads to a different set of tensions. If practice provides the funding, then the research agenda is largely determined by practitioners, and when research bodies provide the funding, the agenda is largely determined by researchers. Government schemes such as the TSB (Technology Strategy Board) in the UK have been successful in bringing partners together and providing some support for joint working, but in some cases, the situation calls for a partnership that is more responsive to practitioners' needs. This is especially true in a process improvement area such as agile software development.

Over the past few years we have been trying to find a model of collaboration and funding that supports the agendas of individual organisations and the research agendas of individual research teams, while also allowing for appropriate funding and authority. From our own experiences and those of others expressed at conference panels, and researcher and practitioner meetings, we have identified the following key challenges in this kind of collaboration.

Timeliness is a key issue for industry. The rigour, highly prized by academia, has a high cost in terms of time. Practitioners often see research as a long-winded process that will demand time from them but not necessarily provide significant benefit. Research outputs can take many months or sometimes years and from the practitioner's perspective the original issues will have changed, evolved or been superseded. Decisions will have been made based on the information available at the time. Practitioners are also wary of how much of their time a research project will take. Traditional research approaches require time to gather and analyse data in a rigorous fashion rather than answering today's industry-based problems.

Relevance is defined as addressing the needs of one or more different stakeholders (Rosemann and Vessey 2008). Understanding the motivations of the different stakeholders is vital to ensure outputs are relevant. Relationship building is essential in order for academics to work closely with practitioners to understand context and business realities resulting in outputs that meet the needs of both stakeholder groups.

Industry seeks solutions to specific problems in a specific context. Academics, more often are concerned with generalisations and theory building. Research outputs need to be crafted in different ways to be relevant to different stakeholder groups. Typical academic outputs focus on positioning the work within an existing field, arguing for the suitability of the research approach, and providing quality analysis and interpretation of data. Practitioners seek palatable solutions to specific problems or seek to learn about new tools or techniques. This is evidenced by the experience reports presented at many practitioner conferences; while they represent valuable reflections on experience, they often provide a more anecdotal focus on tools, practices or techniques. 
Rigour. Quality research outputs require rigorous investigations, which are not necessarily compatible with commercial pressures. Practitioners will always be pragmatic at overcoming any challenges they face, and although solutions to a problem may be found, it is rare for thorough evaluation of any solutions or changes to take place. Rigour and timeliness are two sides of the same argument, and are closely inter-twined.

Access Academic research is usually written for an academic audience and is often written in a format that is not appropriate for practitioners. Despite there being a wealth of knowledge available, few practitioners have the time, inclination or access to delve into existing research on a particular topic. While some professional organisation magazines provide useful summaries of research targeted at practitioners, few of these articles exist (e.g. IEEE Software Voice of Evidence column).

In the next section we discuss related work, in section 3 we introduce the Agile Research Network and the collaboration model followed, in section 4 we describe examples from our case studies so far, in section 5 we describe the lessons learned, and we end with some conclusions. This paper is an extended version of Sharp et al. (2014); the related work section (section 2 ) is new; the evolution of the collaboration model is discussed (section 4.3); a new case study (section 4.4) has been added and lessons learned expanded (section 5).

\section{RELATED WORK}

\subsection{Empirical studies of agile research}

Early critiques of published studies in agile software development identified a number of problems including a lack of empirical research, disparate topics of study leading to a lack of research depth, a focus on XP and agile adoption rather than mature teams, and little industrial impact (Erikson 2005).

A systematic review of empirical studies of agile software development found that the lack of empirical research meant there was little evidence about the benefits and limitations of agile methods (Dingsøyr et al. 2008 ). This review resulted in a roadmap for research which proposed more empirical research, better connections with established research fields, looking at management-oriented methods and investigating core agile ideas. Abrahamsson et al. (2009) noted that while more research was being done, agile methods were still driven by consultants and practitioners, that there was a lack of research rigour, and that researchers needed to address core questions such as what constitutes agility, how agile methods can be extended, and how mature teams use agile methods. More recently, Dingsøyr et al. (2012) analysed existing research into agile development through publications and citations, showing a growing body of empirical research with increasing numbers of academic publications. The spread of publications indicates that research is being undertaken within diverse academic communities. The authors note that there is a more mature research environment in which a variety of themes are being investigated such as estimation, project management, team work, distributed cognition, user-centred design and patterns. A wide range of theoretical perspectives are also being used to inform this research including theories of knowledge management, personality, complex adaptive systems, teamwork, and game theory amongst others. They give a perspective on the evolution of the field, directions for future research, and conclude that both the quantity and quality of agile research has improved. However, they also suggest that more attention needs to be paid to the theoretical underpinnings of agile software development and its practices.

\subsection{Research methods in agile research}

A variety of research methods have been used to investigate the practice of agile development. Surveys (Doyle et al., 2014; Cohn and Rubin 2014; Murphy et al. 2013) and case studies (Laanti et al. 2011; Lagerber et al. 2013) are common. Surveys are often used to quantify trends across populations, and have been used to map the uptake of agile methods; case studies look at specific contexts to understand factors such as the impact of agile adoption in organisations, and current practices. As agile methods are used in complex environments, qualitative approaches are often found using specific methods such as ethnography (Sharp and Robinson 2004), grounded theory (Baskerville et al. 2013; van Waandenburg and van Vliet 2013), interaction analysis (Plonka et al. in press), and action research (Svejvig and Nielsen 2010). Qualitative methods are used to study social practice within a natural setting, and therefore allow for a richer understanding of 'what' practitioners do and 'how' things occur as they do it, in order to then build theory. However, in the conference literature there is also a tradition of publishing experience reports which has attracted some practitioners to conferences. Other quantitative approaches used include experimental research with students (Mendes et al. 2004), and constrained studies with practitioners (Arisholm et al. 2007).

\subsection{Action research}

Action research is often used in industrial settings where "research informs practice and practice informs research" (Avison et al. 1999). An incremental approach of "plan, act, observe, reflect" is used to promote practical problem solving, expand knowledge and improve the skill levels of the actors involved. In the action research process "particular linked ideas are used in a methodology to investigate an area of interest"; these are declared at the beginning to ensure transparency and to enable the subsequent outcome to be judged (Baskerville and WoodHarper 1996). 
Action research approaches have been used successfully in the fields of information systems and software engineering (Baskerville and Myers 2004) and there are examples of their use in agile software development (Svejvig et al. 2010). Action research focuses on the social domain to be researched and the problems that need to be addressed, but often takes an organisational perspective (Checkland and Holwell 2007).

Dittrich et al. (2007) developed a more practitioner-focused approach, 'cooperative method development' (CMD) that adapts action research concepts to software development practices. CMD seeks to address questions such as "How do software development practitioners tackle their everyday work" and "How can methods, processes and tools be improved to address the problems experienced by practitioners?". CMD defines three phases that can be repeatedly applied in the same context: 1 . Understanding practice; 2. Deliberate improvements; and 3. Implement and Observe improvements.

The approach we follow, as discussed in section 3, is not dissimilar from CMD; in particular, we carry out qualitative research, take into account the practitioner's perspective and work within a collaborative setting of researchers and practitioners.

\subsection{Collaboration models}

Collaborations between academia and industry have attracted considerable interest and different models have been proposed to facilitate the transfer of knowledge, technology, skills, and experiences (Gray et al. 2011). Science parks, usually created by a higher education institution in collaboration with companies, to provide an infrastructure where new businesses can be created, are one such model focused on promoting entrepreneurship and innovation (Vardiman and Mhlanga 2010). Other types of university-industry collaborations are (i) problem solving, with industry approaching academia for specifc problems, (ii) technology development, focusing on new or improving technologies, (iii) ideas testing, focusing on testing commercially sound research ideas, and (iv) knowledge generation, where academic research informs projects with anticipated challenges (Perkmann and Walsh 2011). Rieger (2008) presented four primary models of academic-industry partnerships in the United States observed over a period of 10 years. These are (i) academic-led case study or survey focused on strategic industrial issues, and the broad dissemination of results with the goal of attracting sponsorship, (ii) direct student placement in industry with industry-specific education, and internships, (iii) events and programmes focused on highlighting the expertise of a research centre or researcher in order to attract sponsorship, and (iv) membership of industrial partners at varying levels of sponsorship fees in order to fund different research activities.

Benefits and risks of collaboration between academics and practitioners have been highlighted in the literature (Kieser and Leiner 2012; Shani and Coglan 2014). Academia benefits from funding opportunities, empirical data, critical input from industry, and the establishment of new areas of research expertise (Lamprecht and van Rooyen 2012). Industry benefits from rapid access to research outcomes, and graduates specialized in their development area (Parker 1992). Risks of collaboration between academia and industry concern issues such as intellectual property rights, or academics' view of the small and medium enterprise sector as incapable of generating "cutting edge" research (Lockett et al. 2008 as cited in Gray et al. 2011). Academics and practitioners work also to different timescales, with academic projects carrying on for several years, and business seeking quick results. Outcomes of research collaborations are also seen from different perspectives: what matters for business is the impact of the research on a company's performance, products, and processes (Pertuze et al. 2010), while academics are more concerned with their contribution to a research area that may fail to materialise in tangible impact for the involved businesses (Pertuze et al. 2010). Finally, challenges to rigour can also result from practitioners wanting to apply relevant research they may come across straight away without always evaluating its application cleanly.

The risks discussed above are evident in 'Mode 1' research which adopts scientific principles and provides results of interest and value only to the academic community with poor business benefit (Huff and Huff 2001). Management research has proposed 'Mode 2' research (Gibbons et al. 1994; Maclean et al. 2002) that emerged to provide academic rigour and practical relevance via multi-stakeholder (academics and practitioners) teams that work collaboratively on problems in practice (Gray et al. 2011). This approach is based on a series of principles that include: problem solving within the context of application; transdisciplinary problem solving with crossover between theory and empirical elements; heterogeneous teams; social accountability of the research outcomes with a deeper understanding of others' points of view; and, quality controls that go beyond the academic peer review process and reflect the practical side and impact of the research.

Based on the 'Mode 2' approach, Hartley and Benington (2006) suggest that establishing longer-term and deeper relationships between academics and practitioners helps develop trust and promote 'inter-group learning'. They defend the creation of a consortium of 'organisations committed to long-term strategic research with academics' (p.466). This will support 'forward-looking strategic research' that is also relevant to practitioners. The consortium's priorities are agreed between academics and organisations as a result of discussions of their different perspectives, interests, values and priorities.

\section{AGILE RESEARCH NETWORK (ARN)}

The Agile Research Network (ARN, agileresearchnetwork.org) was set up in response to the issues described above as a collaboration between The Open University (OU) and University of Central Lancashire (UCLan) in the UK. ARN is 
currently supported by the universities themselves and funded by the DSDM Consortium (dsdm.org). ARN seeks to work closely with agile practitioners in their place of work investigating practitioner-identified challenges; these may include, for example, understanding the implications and influences agile methods have on organisations and individuals, or assessing the scope and nature of their effectiveness. The ARN then disseminates findings to a wider audience. ARN researchers differ from consultants because they have time to investigate, observe and understand the problem situation; they work cooperatively with collaborators but they remain fully in charge of any changes they wish to make; they use a model to structure their intervention and document their process throughout; unlike a consultant, they are not answerable to management; they are not selling a particular methodology; and they do not hold back from highlighting deficiencies in methods where they find them.

To address each of the concerns listed above the ARN has designed and implemented the approach shown in Figure 1. The approach has four distinct phases: Collaboration kick-off, Investigation, Implementation and Evaluation. It is timeboxed and during each phase ARN researchers work closely with the organisation concerned. In addition, the organisation will have had some contact with the research team before the collaboration kick-off starts. Specifically, collaborators are identified through a call for challenges distributed to the DSDM mailing list, and the challenges are discussed and initially assessed for suitability by the ARN team before the kick-off meeting. This means that organisations approach the ARN team rather than the other way around.

\section{Agile Research Network Approach}

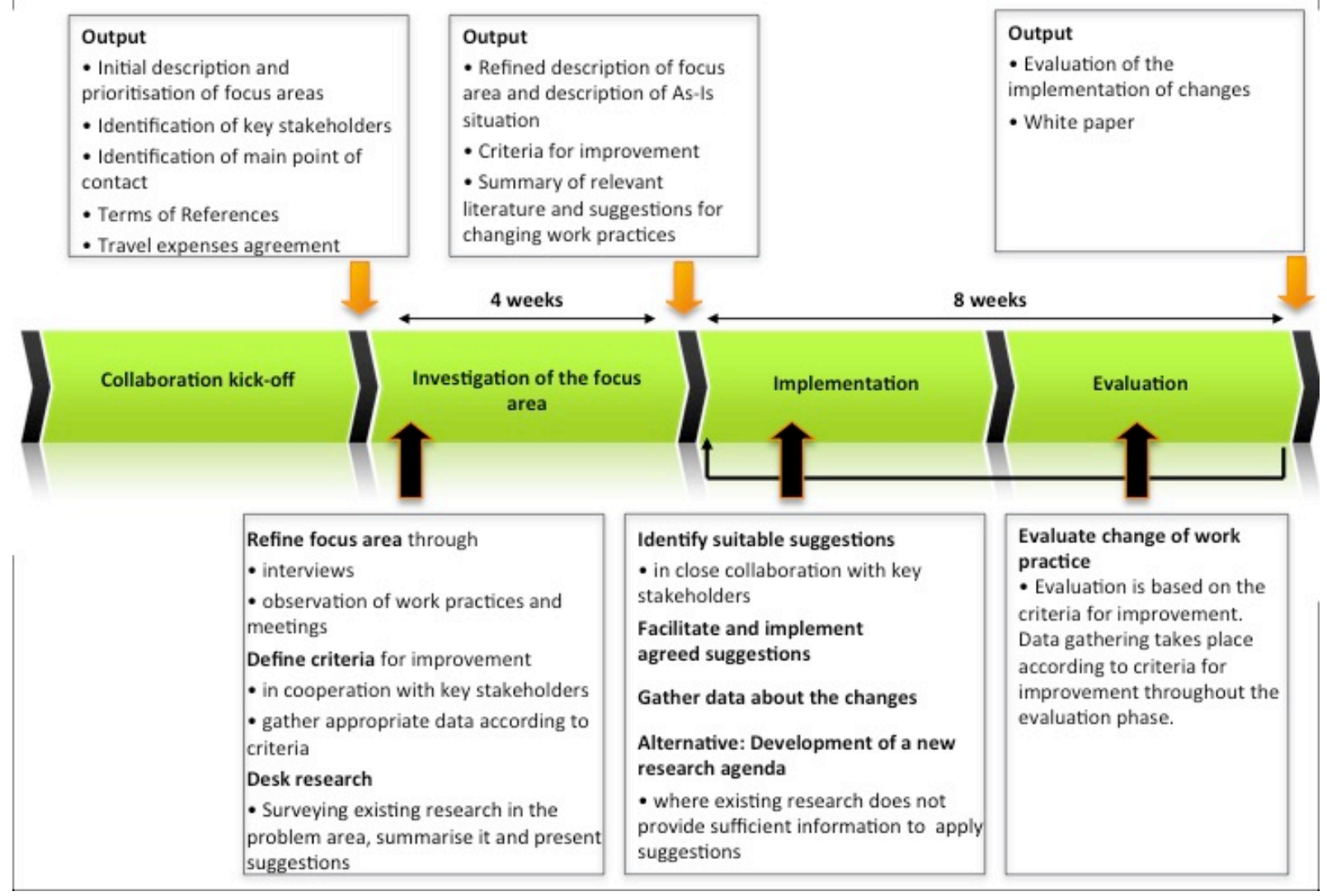

Fig.1 The Agile Research Network collaboration model

In Collaboration kick-off, the organisation and research team discuss the challenge (focus area) and decide how best to proceed. The challenge is appropriate if:

- the researchers already have some understanding or expertise in the area

- literature exists specifically in the area or in a related area

- the challenge is significant enough to the organisation to maintain their engagement throughout the investigation

A gatekeeper for the organisation is identified, a collaboration agreement is drawn up and a start date agreed. 
During Investigation, researchers spend time at the organisation scoping and defining the focus area in detail. Different research methods may be applied to investigate the challenge and identify how improvements could be evaluated at the evaluation stage. Then relevant existing research and literature in the problem area is surveyed and summarised. This tailored literature review and specific suggestions are presented to the stakeholders.

At the Implementation stage, the organisation decides whether to adopt any of the suggestions presented. If they do, the research team facilitates the implementation of new ways of working. Alternatively, where existing research cannot provide suggestions or suggestions are not suitable for the context, a research agenda to investigate the challenge area in more detail can be developed.

During the Evaluation phase, the research team evaluates the changes implemented at the organisation. The evaluation can include quantitative or qualitative measurements.

The ARN model addresses the concerns highlighted in section 1 as follows:

\section{Timeliness}

The model uses short iterative research cycles. The timeframes shown on the model relate to 12 weeks of effort (i.e. the amount of time dedicated to the project) rather than elapsed time, as researchers are not full time and business priorities dictate access. If there is insufficient information on the challenge area and a new research agenda is developed a new timeline is set up.

\section{Relevance and Rigour}

At the end of each research cycle feedback is sought from the organisation to ensure that the challenges being addressed are still relevant and that we have understood the context correctly. Also, during each collaboration, the dialogue between researchers and practitioners is ongoing, permitting valuable reflection on both sides. This constant feedback between researchers and stakeholders increases the rigour of our process and our findings, and allows practitioners to assess and move forward in the areas where there is most value.

\section{Access}

As academics the research team have access to a wide range of research literature. They are able to search, synthesise and present this in a format that is useful in specific contexts, relating the research to practice, making it more accessible to practitioners.

The outputs are also widely available to a range of stakeholders. Each engagement aims to produce a specific report and presentation for the organisation, a practitioner-focused whitepaper and an academic (e.g. research) output.

\section{EXAMPLES FROM OUR WORK}

Up to now, the ARN approach has been applied in three case studies, one of which is still going on. The first case study was conducted in collaboration with a hi-tech software development company that approached the ARN with the challenge of integrating user experience (UX) design into a DSDM project. For the second case study the ARN worked with an organisation that faced the challenge of running agile projects and reporting agile progress in a non-agile environment. For the third case study, which is still in progress, the ARN is working with an organisation that wants to understand how to measure value in agile projects.

Below, we present examples of how the ARN approach addressed the challenges of Timeliness, Relevance and Rigour, and Access in each of the two case studies that have reached a stable phase in the collaboration; we then introduce an enhancement to the approach used in these two case studies and discuss the current third case study in progress following this enhancement.

\subsection{First case study: Integrating UX design into a DSDM project}

This case study focuses on a small independent high-tech software development company that offers technical services across a broad range of industries, languages and platforms. They have tried many flavours of agile, and are actively using a few. They are a founding member of the DSDM Consortium.

\section{Challenge}

The challenge faced by this organization was to integrate UX design into a DSDM project. This is a challenge common to many agile teams, not only those using DSDM. Although the work of UX designers and developers complements each other, the different goals, processes, and working practices of each of these two groups pose challenges in practice.

\section{Timeliness}


The majority of the case study took place between April and October 2013. After all collaboration documents were agreed in April 2013, the investigation phase took place between May and July 2013. Based on the findings of the investigation phase the first major output for the company, the suggestions for improvement were presented to company employees at the end of July 2013. The second major output for practitioners, the white paper (Sharp et al. 2014a), was jointly written with the company during September/October and was presented and published in October 2013. This received over 300 downloads in the first week.

Despite the timely delivery of the practitioner-focused outputs, we encountered some difficulties. For example, the investigation phase required some flexibility in terms of the researchers' time as the activities during that phase were driven by the availability of our point of contact and other key stakeholders, as well as the project priorities. The project focus varied from timebox to timebox and while in some timeboxes several UX design related activities took place, in other timeboxes the development team focused exclusively on the technical implementation. This meant that there were times in which our investigation did not progress as quickly as we had initially expected.

\section{Relevance and Rigour}

The suggestions for improvement did not cover all the existing literature in the area, but were selected specifically for the organisation's situation. The organization's employees recognized this, and agreed that our suggestions were relevant for them. In addition, the timeliness of our feedback meant that the issue was still relevant to their everyday working.

During the investigation phase (May to July 2013), we regularly met informally with the managing director and project manager to discuss our observations and findings. These conversations allowed the company to reflect on their challenges early in the case study and supported us in producing rigorous research outputs by evaluating our observations and interpretations. They also led to joint understanding of the challenge area and informed the next steps of our data gathering i.e. who to interview next, and what kind of questions to ask to investigate the most relevant aspects of the challenge.

\section{Access}

In July 2013, at the end of the investigation phase, we set up a two hour meeting with the company to discuss the challenges we had identified through the data gathering, and to suggest alternative ways of working based on existing literature. For this meeting, we reviewed a wide range of literature including papers published at conferences and in journals, books and websites. We identified applicable suggestions based on nine papers published at conferences, two journal papers, one book and two websites; the practitioners were not aware previously of the suggested literature. Project leads from this case study reported that the suggestions for improvements were very useful and were actively discussed by the project team. This project has also led to the authoring of a DSDM pocket book on UX to be available from the DSDM consortium (DSDM Consortium 2015).

\subsection{Second case study: Reporting agile progress in non-agile environments}

For this case study we worked with the London office of a large multinational organization that operates in a regulated environment. The London office adopted DSDM because it covers the whole project lifecycle and provides a framework that supports the governance needed in a regulated environment.

\section{Challenge}

The challenge for the London office of this company was to run agile projects and report agile progress to the parent company whose processes were plan-driven, i.e. they were running agile projects in a non-agile management environment. Their projects are approved, budgeted and monitored by their Headquarters using a traditional waterfall approach.

\section{Timeliness}

The first point of contact with the organisation was in May 2013 and the case study started in July 2013 after a suitable challenge was identified and the collaboration was set up. After a first investigation of the challenge area, we conducted interviews with different stakeholders in August 2013 and analysed the data in September/October 2013. We discussed the findings and remaining open questions with key stakeholders in November 2013 and presented the suggestions for improvements back to the organisation in December 2013.

The suggestions were considered to be useful and a white paper (Plonka et al 2014) was written and approved by the company.

\section{Relevance and Rigour}

Although one specific challenge area was identified during the collaboration kick off, interviews with staff during the investigation phase revealed a range of different challenges and different perspectives. Towards the end of the investigation 
phase, we had to decide which challenge(s) to focus on when reviewing existing literature. This was discussed with the main point of contact in order to present the different challenge areas and to identify the most relevant areas for their organisation.

\section{Access}

In December 2013, we presented suggestions back to the organisation on four different challenge areas. Research was sparse; in total we found eleven papers for the challenge areas that were relevant to the company's situation. The organization engaged in an ongoing discussion, adopted some of our comments, and identified further areas that could be adopted in addition to the changes already made.

\subsection{An Enhanced ARN Approach}

As a result of reflection from the first two case studies the ARN collaboration model was enhanced slightly for the third case study (see Figure 2). As the figure shows, the second stage of the approach, Investigation of the focus area, was enhanced by a second strand of investigation to address a supplementary area. The key characteristics of this supplementary area are:

1. that it is easily identifiable through the Collaboration kick-off conversations with the collaborators, and

2. that there is existing research available that the researchers know well and can see benefit in applying in the current situation

During the first week of the investigation phase, the supplementary area(s) are identified and agreed with the collaborators, the suggestions for improvement are identified, and the suggestions are presented to the collaborators. This relies on the area itself being clearly defined and well understood within the context, and on the related research being readily available and well known by the researchers. During the second week, the specific suggestions (if any) to be implemented are identified and agreed, and during the third and fourth weeks evaluation of any change begins. The evaluation may continue beyond this specific phase, and will feed into the overall evaluation output and white paper. Investigation of the main focus area continues during this time.

The other phases of the approach are conducted as in the original diagram (Figure 1), and the main focus area continues to be investigated, implemented and evaluated as described above. The only difference was to add a supplementary focus area.

There were two main drivers for this change. Firstly, there were many different issues raised during the collaboration kick-off for both of the first two case studies, and in some cases the researchers were aware of useful suggestions that might improve the situation. These suggestions tended to arise during the interactions between researchers and the organization, and hence were being fed into the organisation anyway, but they were not being tracked or evaluated. By being more explicit about the areas, it was hoped that a more disciplined evaluation of these supplementary areas could be conducted. Secondly, much time during this investigation phase was spent on interviews and understanding the organisation in more detail, and it was felt that more could be made of this effort to capture changes that were happening as a result of the ARN presence. 


\section{Enhanced Approach: Investigation phase}

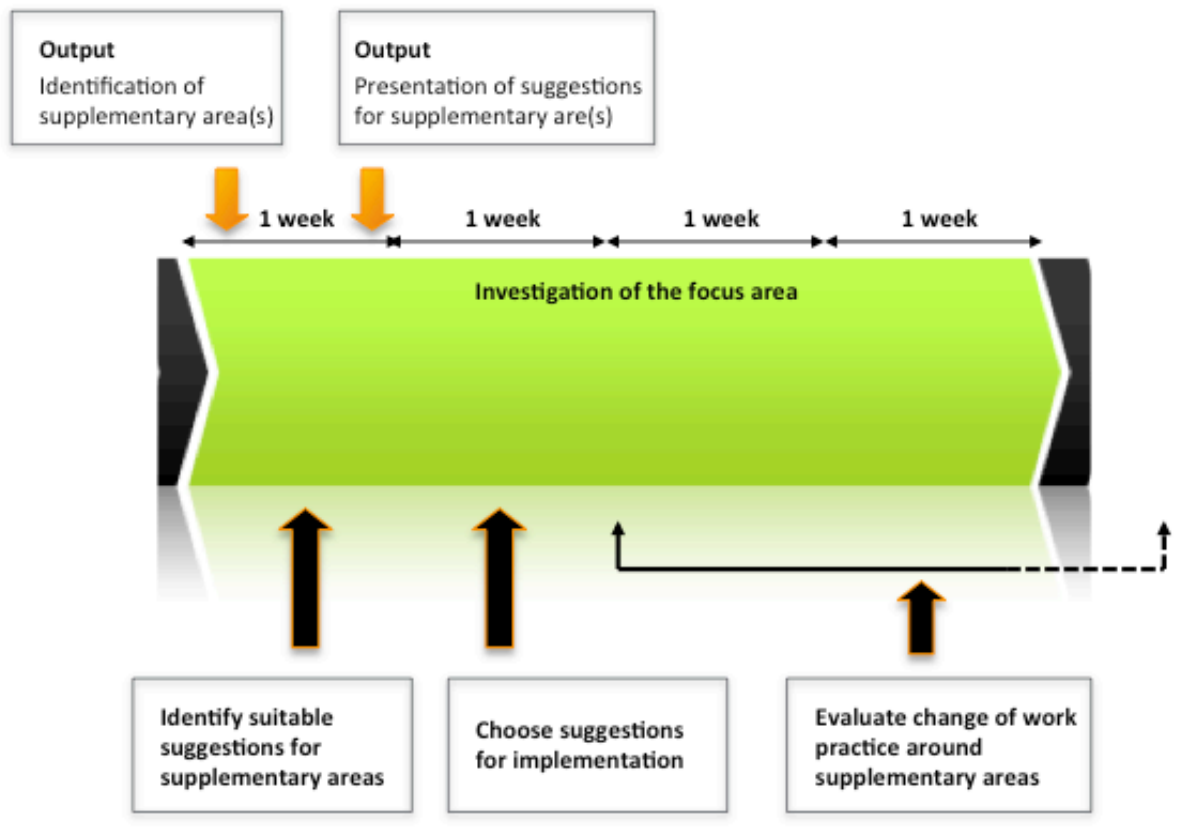

Fig. 2 The enhanced Agile Research Network approach collaboration model. (Note: Investigation of the focus area continues alongside work on the supplementary area, and all the other stages are performed as shown in Figure 1)

\subsection{Third case study (in progress): Measuring value in agile projects}

For this case study we are working with a big multi-national insurance company who has a large and distributed group in the UK working across different commercial and personal insurance areas. They are recent agile adopters who chose DSDM because it provides a flexible framework for running projects in a range of different ways.

\section{Challenges}

For this case we used the enhanced model as presented in Figure 2. The chosen focus area was to determine how to measure value in agile projects, at portfolio, team and individual levels. This was a strategic focus for the organisation. The objective was to ensure that new measures were not merely bureaucratic but would better assess whether agile approaches had a positive impact on project outcomes.

There were three supplementary areas that arose during Collaboration kick-off, and which related to existing research well known to the team. These areas and research were: inter-team knowledge sharing (Santos et al. 2013); business and customer involvement in agile teams (Martin 2009); and how to spread coaching expertise throughout the development teams (Hanly et al. 2006). Although the information was regarded as useful and relevant by our contacts, these suggestions were not explicitly taken up by the organization during the investigation phase. Instead, another supplementary area for evaluation was highlighted by the teams, which was already undergoing change anyway. This was to implement an electronic whiteboard (visual team-level information radiator) to improve communication between on-site and off-site team members.

\section{Timeliness}

This case study had a long lead-in period. The company first contacted ARN in March 2013 when the first call for collaborators was made. At this stage they were just about to start running agile projects and did not appear confident enough to let the research team in. The ARN contacted the project manager and, portfolio manager a year later, and they involved the Head of Business Change who then signed off the project.

The case study visits took place between March and July 2014. Feedback on the three supplementary areas mentioned above took place in June and on the primary challenge in October 2014. 
Because it took so long for the organisation to decide which supplementary idea to implement, there was less parallel running than we had anticipated. Although evaluation started at the end of July, it was hampered by a protracted vacation period during which numerous key players were absent. The evaluation was still going on after the feedback session for the focus area.

\section{Relevance and Rigour}

The enhanced research model gave us two distinct areas to work on, both of which the organization said were valuable. The focus area challenge was a complex concept that required in-depth investigation and contextual understanding. The supplementary challenge was a quick return practice-based change that the organisation was able to implement for us to evaluate. Even though this took some time to set up, we felt that the discussions we had with the project manager who was instigating the change helped to clarify and influence his ideas.

\section{Access}

The enhanced research process has resulted in us giving more frequent feedback to the organization. We fed back suggestions about the supplementary challenges very early in the research process, and later presented findings about the focus area at the end of the investigation stage.

\section{LESSONS LEARNED}

The ARN is still in the early days of using this collaboration model as the end of the Investigation stage was only reached with two organisations, with a third organisation in the middle of Investigation. However, the two first projects have yielded valuable results and led to the integration of research and practice; they have also led us to adapt the initial model as discussed in subsection 4.3. Here we discuss some of the lessons learned.

\section{Building trust}

An advantage of the time-boxed approach is that trust is built with collaborators by giving feedback early and frequently. One way to do this is by making regular visits during the Investigation stage and giving verbal feedback about ideas and progress at each meeting. This helps check that collaborators are happy with progress. When we write papers, we always show our work to collaborators and encourage them to add to it. By getting regular feedback both for research and writing helps to promote continuous improvement. We have noticed that change starts happening as soon as we engage with practitioners. The decision about which changes to make is left with the organisation, so the implementation cycle belongs more to the organisation than it does to us.

It is also important to engage with people at the right level of seniority, and to build enough trust to get to the next stage. Conditions need to be right before gaining acceptance for the research collaboration to start.

\section{Appropriate contracts}

Written agreement at the beginning of the project needs to be in place before starting any work. This level of formality helps the smooth running of the project. A non-disclosure agreement also needs to be signed. This ensures that we get buy-in from everyone who is likely to be involved. At the Collaboration kick-off stage we often talk to managers, and this is important in order to get managerial approval. However, working with agile team members, also requires buy-in from those individuals. Although there is always one point of contact, it is a good idea to set up a secondary contact, as in both of our initial projects we had problems when our contact was on holiday.

\section{Flexibility}

Maintaining a flexible approach to accommodate changes in the projects is important. We have also found a full-time researcher essential in order to maintain this flexibility. For example flexibility in the timing of visits to the host organisation, and the need to be able to arrange a visit at short notice, or delay a visit depending on circumstances. Taking business priorities into consideration inevitably had consequences to our timeline. However, having an incremental model for delivering outputs allows us to capture what we have learned in a timely manner.

\section{Outputs tailored to specific audiences}

One of our aims has been to produce accessible papers that are tailored to different audiences. In all case studies, the first output has been a feedback session tailored to the collaborator organization. The second has been a white paper aimed at the practitioner community. This highlights the challenges found in the case study, summarises the relevant literature and identifies successful changes and areas of best practice. These white papers are freely available on the project website (agileresearchnetwork.org). By doing this we aim to show that research outputs can be made accessible, to show agile practitioners that they are not alone, and to enhance understanding of how agile methods are used in practice. In our academic papers we highlight the richness and complexity of investigating challenges faced in organisations. 


\section{Funding}

The current funding model has run for about 18 months, and has been renewed for another year. We ask collaborators to pay for our travel, as we believe that paying for some part of the research helps to seal their commitment to its value. We are investigating models that will help sustain the collaborations.

\section{Research expertise}

The three case studies so far have drawn on the research team's expertise. We would not be able to take on board any organisational challenge for which the team did not already have some level of expertise. However, once the investigation starts it has often taken unexpected turns and this approach has been a learning experience for the team, and has widened our knowledge of the literature. It has also created opportunities to take the research a step forward; for one of the case studies we published a case study, for another we have surveyed practitioners to expand the findings of the associated white paper, and in the third we have been evaluating the impact of using an electronic whiteboard.

\section{Keeping presence}

We need to maintain a regular contact with the organization to make sure that our agreed agendas do not start diverging and losing priory. There are so many demands on busy practitioners that research will easily drop out if we don't keep a regular presence and if the relevance of the collaboration is not clear. As practitioners take on board what researchers say and apply it if relevant, this may not always be made explicitly visible to researchers, in particular if a regular presence is not maintained. We also noticed that when the researchers were not visible (for example during the vacation period), the project activities carried out by practitioners tended to diminish.

\section{Too much choice can be overwhelming}

When faced with a large lists of challenges we need to give feedback to the organization to help them to narrow the scope and prioritize what is to be addressed. This should take into account what is more relevant to the organization but also the existence of research in the area on which to build.

\section{Too much information can be overwhelming}

If we identify a main challenge that requires more in-depth and longer term work, it may be useful to also identify a more practical supplementary challenge on which to deliver quickly so we have the time to work on the main challenge in an agile and incremental way. In the third case study, we used an enhanced model to accommodate exactly this. The change was driven by the experience of the first two case studies, and we identified and made suggestions in three areas that were in the original list of main challenges. However none of the three areas we identified and presented suggestions on were explicitly taken forward. On reflection, giving so much information at one time was overwhelming and the teams instead surfaced an issue that was closer to their day-to-day practice that needed evaluation.

\section{CONCLUSION}

So far, we have applied a model of collaboration to study three very different organisations; they have provided different challenges requiring different data gathering methods and have produced different outcomes. Whilst our collaboration model produced results in the first two case studies, after reflection we felt it would be improved by modification before being applied to the third case study. Its strengths are that researchers engage with collaborators in an in-depth way, spending time in the organization to understand the context and any particular challenges before making suggestions to alternative ways of working; and that research is tailored to each organization individually.

The outcomes produced from each challenge are dependent on the uniqueness of the context and level of available literature. For example, in the first case there was sufficient literature for us to synthesise and summarise for practitioner use. In the second, there was less existing literature, and although sufficient to make relevant suggestions, we identified that the challenge of using agile in a non-agile environment is an under-researched area that could be added to the research agenda in this area.

The collaborations have resulted in greater expertise of the researchers through a wider knowledge of the literature but also creating opportunities to work with data generated by the collaborations. Apart from the challenges identified with collaborators, we have also collected a range of other challenges in conferences and workshops.

In terms of our original aims, the proposed model does help to bridge the gap between research and practice, and has been shown to bring relevant and valuable research to bear on practitioner challenges. However the model continues to evolve in terms of funding, timelines and research rigour.

\section{ACKNOWLEDGMENTS}

We would like to thank our collaborators and the Dynamic Systems Development Method (DSDM) consortium. 


\section{REFERENCES}

Abrahamsson, P., Conboy, K. and Wang, X. (2009) Lots Done, More to Do: The Current State of Agile.European Journal of Information Systems, 18:281-284

Agerfalk, P. and Fitzgerald, B. (2006) Flexible and Distributed Software Processes: Old Petunias in New Bowls? Communications of the ACM, 10(49):27-34

Arisholm, E., Gallis, H. and Dyba, T. (2007) Evaluating Pair Programming with Respect to System Complexity and Programmer Expertise. IEEE Transactions on Software Engineering33(2):65-86

Avison, D. E., Lau, F., Myers, M. D. and Nielsen, P. A. (1999) Action research. Communications of the ACM, 42(1):94-97

Baskerville, R. and Myers, M. D. (2004) Special Issue on Action Research in Information Systems: Making IS Research Relevant to Practice - Forward. MIS Quarterly, 28(3):329-335

Baskerville, R., Pries-Heje, J. and Madsen, S. (2011) Post-agility: What follows a decade of agility? Information and Software Technology, 53(5):543-555. http://linkinghub.elsevier.com/retrieve/pii/S0950584910001953 [Accessed June 30, 2014]

Beck, K. (2000) Extreme Programming Explained: Embrace Change, Addison-Wesley

Cao, L. and Balasubramaniam, R. (2008) Agile Requirements Engineering Practices: An Empirical Study. IEEE Software, 25(1):60-67

Checkland, P. and Holwell, S. (2007) Action Research. In Kock, N. (Ed.) Information Systems Action Research. Springer US Cockburn, A. (2004) Crystal Clear: A Human-Powered Methodology for Small Teams, Addison-Wesley

Dingsøyr, T., Dyba, T. and Abrahamsson, P. (2008) A Preliminary Roadmap for Empirical Research on Agile Software Development. Agile 2008. Toronto, Canada, IEEE Press

Dingsoyr, T., Nerur, S., Balijepally, V. and Moe, N. B. (2012) A Decade of Agile Methodologies: Towards Explaining Agile Software Development. The Journal of Systems and Software, 85:1213-1221

Dittrich, Y., Rönkkö, K., Eriksson, J., Hansson, C. Lindeberg and Olle, L.(2007) Cooperative method development. Empirical Software Engineering, 13(3):231-260

Doyle, M., Williams, L., Conh, M. and Rubin, K. (2014) Agile Software Development in Practice. In G. Cantoneand M. Marchesi, eds. XP. Springer, 32-45. http://collaboration.csc.ncsu.edu/laurie/Papers/xp2014_submission_51.pdf [Accessed October 13, 2014]

DSDM Consortium (2012) The DSDM Agile Project Framework Pocketbook. DSDM Consortium DSDM Consortium (2015) The DSDM UX Pocketbook. DSDM Consortium (to appear)

Dybå, T. and Dingsøyr, T. (2008) Empirical Studies of Agile Software Development: A Systematic Review. Information and SoftwareTechnology, 50:833-859

Erikson, J., Lyytinen, K. and Siau, K. (2005) Agile Modeling, Agile Software Development, and Extreme Programming: The State of Research. Journal of Database Management, 16(4):88-100

Fitzgerald, B., Hartnett, G. and Conboy, K. (2006) Customising Agile Methods to Software Practices at Intel Shannon. European Journal of Information Systems, 15:200-213

Gibbons, M., Limoges, C., Nowotony, H., Schwartzman, S., Scott, P. and Trow, M. (1994). The New Production of Knowledge: the dynamics of science and research in contemporary societies. Sage Publications, London

Gray, D., Illes,P. andWatson, S. (2011) Spanning the HRD Academic Practitioner Divide - Bridging the Gap through Mode 2 Research, Journal of European Industrial Training , 35(3):247-263

Gregory, P., Plonka, L, Sharp, H., and Taylor, K.J. (2014) Bridging the Gap between Research and Practice: the Agile Research Network in Proceedings of European Conference on Research Methodology (ECRM), June, London

Hanly, S., Waite, L., Meadows, L. and Leaton, R. (2006) Agile Coaching in British Telecom: Making Strawberry Jam in Proceedings of Agile 2006

Hartley, J. andBenington, J. (2006) Copy and paste, or graft and transplant? Knowledge sharing through inter-organizational networks. Public Money and Management 26(2):101-108

Highsmith (2002) Agile software development ecosystems, Addison Wesley Professional

Huff, A. S. and Huff, J. O. (2001). Re-Focusing the Business School Agenda. British Journal of Management, Blackwell Publishers Ltd, 12:S49-S54 
Kieser, A. andLeiner, L. (2012) Collaborate With Practitioners: But Beaware of Collaborative Research. Journal of Management Inquiry, 21:14-28

Laanti, M., Salo, O. and Abrahamsson, P., (2011) Agile methods rapidly replacing traditional methods at Nokia: A survey of opinions on agile transformation. Information and Software Technology, 53(3):276-290.

http://linkinghub.elsevier.com/retrieve/pii/S0950584910002119 [Accessed June 11, 2014]

Lagerberg, L. Tor, S., Emanuelsson, P., Sandahl, K. and Sthahl, D. (2013) The Impact of Agile Principles and Practices on Large-Scale Software Development Projects: A Multiple-Case Study of Two Projects at Ericsson. 2013 ACM / IEEE International Symposium on Empirical Software Engineering and Measurement:348-356.

http://ieeexplore.ieee.org/lpdocs/epic03/wrapper.htm?arnumber=6681378 [Accessed May 27, 2014]

Lamprecht, van Rooyen, g. (2012), Models for Technology Research Collaboration Between Industry and Academia in South Africa, 2012

Lockett, N., Kerr, R. and Robinson, S. (2008) "Multiple Perspectives on the Challenges for Knowledge Transfer between Higher Education Insititutions and Industry. International Small Business Journal 26:661-681

MacLean, D., MacIntosh, R. and Grant, S. (2002) Mode 2 Management Research. British Journal of Management, 13:189207

Martin, A. (2009) The Role of Customers in Extreme Programming Projects, PhD thesis at Victoria University of Wellington Mendes, E., Al-Fakhri, L. B. and Luxton-Reilly, A. (2004) Investigating Pair-Programming in a 2nd-year Software Development and Design Computer Science Course. ACM SIGCSE Bulletin, 37(3):296-300

Murphy, B., Bird, C., Nagappan, N., Zimmermann, T., Williams, L. and Begel, A. (2013) Have Agile Techniques been the Silver Bullet for Software Development at Microsoft? 2013 ACM / IEEE International Symposium on Empirical Software Engineering and Measurement:75-84. http://ieeexplore.ieee.org/lpdocs/epic03/wrapper.htm?arnumber=6681340 [Accessed June 8, 2014]

Parker, L.E. (1992), Industry-University Collaboration in Developed and Developing Countries, the World Bank, September Perkmann, M., Walsh, K. (2010) The Two Faces of Collaboration: Impacts of University Industry Relations on Public Research, Industrial and Corporate Change, 2009

Pertuze, J.,Calder,E., Greitzer, E., and Lucas, W. Best (2010) Practices for Industry-University Collaboration, MITSloan Management Review, 51(4)

Plonka, L., Sharp, H., Barroca, L., Salah, D., Gregory, P. and Taylor, K.J. (2014) Agile projects in a non-agile environment. http://agileresearchnetwork.org/wp-content/uploads/2014/07/Nonagile_environment_WhitePaper.pdf [Accessed October 10, 2014]

Plonka, L., Sharp, H., van der Linden, J. and Dittrich, Y. (in press) Knowledge transfer in pair programming: an in-depth analysis. International Journal of Human-Computer Studies, 73, doi:10.1016/j.ijhcs.2014.09.001

Rieger, C. (2008) Models for Academic/Industry partnerships. A presentation made at the Center for Research on Information Technology and Organisations, University of California at Irvine, February 13, 2008

Rosemann, M., andVessey, I. (2008). Toward improving the relevance of information systems research to practice: the role of applicability checks. MIS Quarterly, 32(1):1-22

Santos, V., Goldman, A., DeSouza, C. and Sharp, H. (2013) 'A Pattern Language for Inter-team Knowledge Sharing in Agile Software Development', PLoP 2013

Schwaber, K. (2004) Agile Software Development with Scrum, Microsoft Press

Shani, A. andCoghlan, D. (2014) Collaborate With Practitioners: An Alternative Perspective A Rejoinder to Kieser and Leiner (2012). Journal of Management Inquiry, 23:433-437

Sharp, H. and Robinson, H. (2004) An Ethnographic Study of XP Practices. Empirical Software Engineering, 9(4):353-375

Sharp, H., Plonka, L., Gregory, P. and Taylor, K.J. (2014a) Integrating UX design into a DSDM project: Challenges, work practices and lessons learned. http://agileresearchnetwork.org/wp-content/uploads/2013/11/DSDM_UX_White_Paperupdate-151113.pdf [Accessed October 10, 2014]

Sharp, H., Plonka, L., Taylor, K.J., and Gregory, A.J. (2014b) Overcoming challenges in Collaboration between research and practice: the Agile Research Network in Proceedings of Software Engineering Research and Industrial Practices (SER\&IP), a workshop co-located at ICSE 2014, 1st June, Hyderabad 
Svejvig, P. and Fladkjær Nielsen, A. (2010) The Dilemma of High Level Planning in Distributed Agile Software Projects: An Action Research Study in a Danish Bank. In Šmite, D., Moe, N. B. and Ågerfalk, P. J. (Eds.) Agility Across Time and Space. Springer Berlin Heidelberg

Van Waardenburg, G. and van Vliet, H. (2013) When agile meets the enterprise. Information and Software Technology, 55(12):2154-2171

Vardiman,P., Mhlanga, F. (2010) Conceptual Models of Collaborative Partnerships and the Infusion of Knowledge Workers in the Local IT Sector, Conference of Information Systems Applied Research, Nashville Tennessee, USA 